\title{
PROGRESSIVE MOVEMENTS
}

\author{
Ix chasan of
}

LUCY L. DROWN

\section{NURSES AS SANITARY INSPECTORS}

\section{BY JOHANNA VON WAGNER}

[Two most interesting and instructive talks were recently given at the Visiting Nurses' Settlement, Orange Valley, by Mrs. Johanna von Wagner, sanitary inspector of Yonkers, New York. The one given in the afternoon was a practical instruction to the visiting nurses on the subject of bad sanitation in dwelling-houses-how it could be discovered and how remedied. Simple, practical remedies within the reach of any intelligent woman were brought to the notice of the nurses. They were also told what unsanitary conditions might be suspected by the appearance of certain diserses. If radical changes seemed desirable, they were urged to use tact in properly reporting casen to the Board of Health, or, what is sometimes far more desirable, to personally call the attention of landlords to defects, together with intelligent suggestions of remedies.

Mrs. von Wagner kindly gave one of the residents a practical explanation of her work by accompanying her the next morning on her daily round of visits. One plumber immediately and without solicitation supplied a ventilating shaft which had been overlooked in some recent work, simply because he heard through the landlord that this oversight had boen discovered by an official inspector.

This instruction to the nurses wan followed in the evening by a talk to some prominent members of the Charity Organization Society-men and women who are keenly alive to public welfare.

Three points were forcibly made: first, that bad sanitation could be remedied often by simple methods which tenants can be taught, also that Boards of Health are ready to listen to criticisms from intelligent sources, and that landlords will often welcome practical, reasonable suggestions for the better housing of their tenants, provided they come from those of recognized authority.

The second point made was the importance of apecial, thorough training on the part of the nurse for this work. Mrs. von Wagner then dwelt on the third point, viz.: the fitness of women for this work of sanitary inspection of the houses of the working classes, and the especial fitness of trained nurses. She herself is the pioneer in a new field of labor for the professional nurse. She recognizes most fully the inestimable benefit of her training and experience in hospital, private, and visiting nursing as a foundation for the work she is now doing.

Already her earnest words have made a deep impression in one town, and it is more than poissible that the office of woman sanitary inspector may be created in many towns and cities as a result of her example in Yonkers. 
This is but another proof that year by year the professional field of usefulness for the nurse is broadening. New positions are being created for her because of her fitness by reason of her training. New opportunities for special training to fit her for these positions are offered as well.

Those outside the profession are watching eagerly and critically to see if she is alive to the signs of the times, and will be ready to fill the posts of responsibility as they lay open before her.-ED.]

THE great problem at the present time seems to be not how best to alleviate suffering, but how to prevent it. To send out nurses to care for the sick poor is certainly necessary as long as we have the sick, but the teaching that goes with the care, how to prevent that sickness another time, and how to care best for the body to keep it well, seems of far more importance. Unless we can do preventive work, it would be covering $u p$ an evil and never eradicating it. So let us who have an opportunity of doing instructive work in the homes of people fit ourselves as teachers and take the gospels of cleanliness, fresh air, pure food and water, hygiene, bodily and domestic, to those who never had a chance of getting that precious knowledge, and help them to apply it practically.

There is no larger ficld for such work than the systematic tenementhouse inspection under the Board of Health in our own cities, going from home to home and coming in contact with all the inhabitants. There is hardly a family one leaves without having given advice or help in some way, or, as one woman remarked the other day, "You did put them on the right road to get over their difficulties." It means giving the people the benefit of our experience and sympathy, that which alone can do lasting good, and which so often will convert evil activities into good.

It is surprising that the need of such work was not recognized long ago. So far as I know, Yonkers is the only city in the United States that has a woman sanitary inspector for tenement-houses. Chicago has six women inspectors, but they seem to confine their work to factories and sweat-shops.

The plea for women as sanitary inspectors cannot be made too strongly nor the benefits overestimated. Women by nature are better teachers than men, and, besides, we are dealing with women in our work, and many times the door is opened to us because we are women and will understand the situation where our men inspectors have great trouble in being admitted, and in some houses, where the conditions are very bad, they sometimes refuse to go.

So the objection made by so many men that a woman is not fitted to visit such places seems unfounded, because it is the woman that 
goes everywhere without fear, and I would say, Why does a city allow such places to exist where it would not be safe for a woman to enter?

Our fellow-men live there and will do so until a reform it brought about, and as a large amount of reform work is inaugurated by women, this field is legitimately woman's sphere.

\section{NURSING THE HAIR}

A TIRED trained nurse had reached the age at which it was no longer possible for her to give to her work the enthusiasm she considered necessary. Her years of labor had brought their reward, and she was able to pause long enough to decide what her work in the future should be.

It was plain that her own profession was too exacting. It was also plain that her new vocation should be in the line of her old employment, as it was too late in life for her to begin anything new. She consulted with her colleagues and with her friends among the physicians. None of them was able to suggest just the employment that suited her case.

The solution of the problem came finally, as most satisfactory things do, through her own inspiration. Then she went to a physician who had become famous in the specialty she proposed to follow and made this proposition to him:

"You're a specialist in the treatment of the hair and have succeeded in acquiring a reputation that brings patients to you from all over the country," she said. "Now, I want to become a nurse for the hair, just as you are a physician for it.

"I know that you always recommend certain exercises to your patients which are to be done by their maids or by some professional masseuse. Now, many of your patients have no maids and would rather be treated by a trained nurse who knows something of hygiene than by a masseuse. I want to be that sort of nurse. Is there any opportunity for a woman to succeed in work of that kind?"

The hair specialist, who happened to be bald himself, met her suggestion with greater enthusiasm than she had hoped for. He was certain that sufficient employment could be found for her.

So the woman gave up the work of regular nursing and set out to devote herself exclusively to the hair. Her first patients came from the physician. The number increased rapidly and she soon had plenty to do. She was able to give more satisfaction to the patients than they had ever before enjoyed because she had all the skill that came from 